\title{
Analysis and Compensation Control of Dead-Time Effect on Space Vector PWM
}

\author{
Jie Shi ${ }^{*}$ and Shihua $\mathrm{Li}^{\dagger}$ \\ ${ }^{* \dagger}$ School of Automation, Southeast University, Nanjing, China
}

\begin{abstract}
Dead-time element must be set into space vector pulsed width modulation signals to avoid short circuits of the inverter. However, the dead-time element distorts the output voltage vector, which deteriorates the performance of electrical machine drive system. In this paper, dead-time effect and its compensation control strategy are analyzed. Based on the analysis, the voltage distortion caused by dead-time is regarded as two disturbances imposed on $d q$ axes in the rotor reference frame, which degenerates the current tracking performance. To inhibit the adverse effect caused by the dead-time, a control scheme using two linear extended state observers is proposed. This method provides a strong ability to suppress dead-time effects. Simulations and experiments are conducted on a permanent magnet synchronous motor drive system to demonstrate the effectiveness of the proposed method.
\end{abstract}

Key words: Current tracking, Dead-time compensation, Extended-state observer, PMSM, SVPWM

\section{INTRODUCTION}

Space vector pulse width modulation (SVPWM), which is based on voltage source inverter (VSI), is one of the most commonly applied modulation techniques to drive electrical machines. The main-current switching device of VSI is the insulated gate bipolar transistor (IGBT). Given that IGBT has finite turn-on time and turn-off time, a proper length of time delay must be imposed between the turn-on signal of one IGBT and the corresponding turn-off signal of the other IGBT within the same leg to avoid possible short circuit. This time delay, known as dead-time, distorts output voltages [1]-[3], [5]-[14]. Notably, for AC motor vector control systems, the commanded voltage vector is given by the current controller, whose objective is to force the actual current vector of the motor to track the reference current vector. The difference between actual voltage vector and commanded voltage vector caused by the dead-time can disturb this objective of current tracking. And this deterioration of current tracking can result in the distortion of phase currents, which leads to the ripples in the electromagnetic torque. Therefore, from the perspective of system control, the purpose of dead-time compensation is to

Manuscript received Aug. 8, 2014; accepted Dec. 24, 2014

Recommended for publication by Editor Kwang-Woon Lee.

†Corresponding Author: 1sh@seu.edu.cn

Tel: +86-25-83793785, Southeast University

*School of Automation, Southeast University, China reject the disturbance caused by the dead-time and improve the performance of current tracking.

Different approaches have been discussed to overcome this problem. These methods can be divided into two main groups. The first group is based on the modification of pulse width modulation (PWM) signals [6]-[8]. Most methods in this group are dependent on the precise detection of current polarity. The modified PWM signals are obtained by off-line calculation or additional hardware circuits. However, obtaining accurate current polarity at zero-crossing instants, where the current amplitude is rather small, is difficult [9], [10]. The other group is based on a feed forward control approach. In this group, a compensating voltage is added to the commanded voltage to counteract the voltage error caused by the dead-time. The compensating voltage can be mainly obtained in two ways. One way calculates the candidate compensating voltages off-line and employs the corresponding one according to the directions of phase currents, such as in [10] and [11]. Therefore, methods belonging to this group also rely on the precise detection of current polarity, which is difficult to achieve. Another way is based on the disturbance observer (DOB). Strategies belonging to this way do not require any additional hardware or accurate detection of current polarity. They consider dead-time as the disturbance voltage vector and obtain the estimate of disturbance via DOB, from which the compensating voltage is acquired [12]-[14]. However, the design of DOBs is based on the precise parameters of motors. 


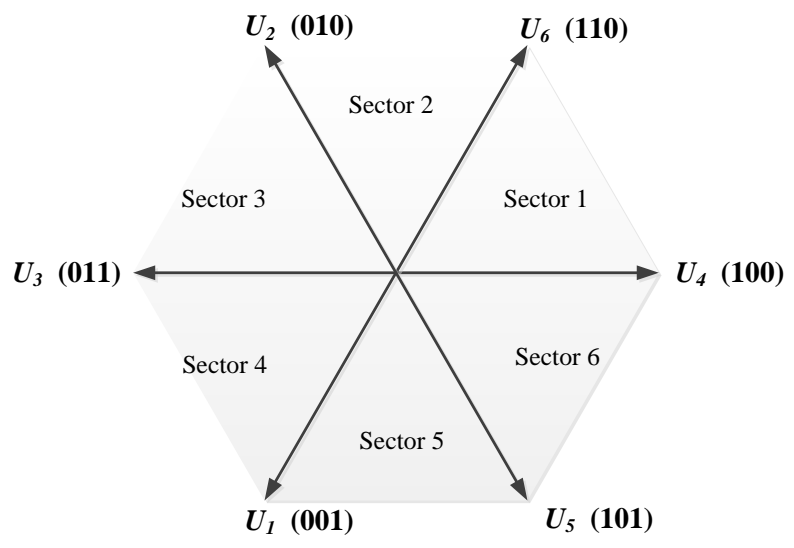

Fig. 1. Six basic nonzero voltage vectors.

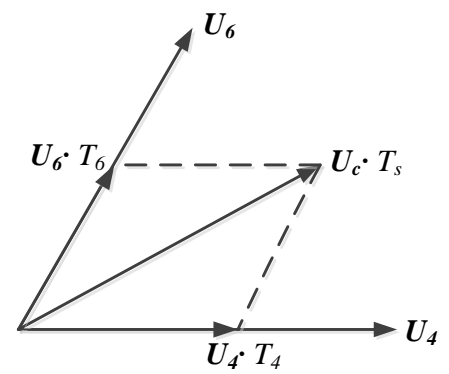

Fig. 2. Case of commanded voltage located in sector 1.

The variations of the parameters, such as resistance varying with temperature and inductance varying with flux density, can affect the accuracy of estimation to some extent.

In this paper, detailed analysis of dead-time effect in the implementation of SVPWM is presented, which scrutinizes the disturbance caused by dead-time and its adverse effect on electrical machine drive system. A control scheme using extended state observer (ESO) is proposed to compensate the dead-time effect. This scheme does not require precise motor parameters or any additional hardware. The dead-time effect is regarded as two disturbance voltages added to the commanded voltages of $d q$ axes in the rotor reference frame, which undermines the performance of current tracking. To reject the disturbance, two linear ESOs are employed to obtain the estimates of the disturbances. The estimates are then delivered to the commanded voltages of $d q$ axes to counteract the disturbances caused by the dead-time. To verify the effectiveness of the proposed control scheme, experiments are conducted on a permanent magnet synchronous motor (PMSM) drive system, and all the algorithms are achieved through digital signal processor (DSP) TMS320F2812.

\section{ANALYSIS ON DEAD-TIME EFFECT}

According to the different combinations of switching states of the inverter, eight basic voltage vectors, including six nonzero vectors $(100,110,010,011,001$, and 101) (Fig. 1)

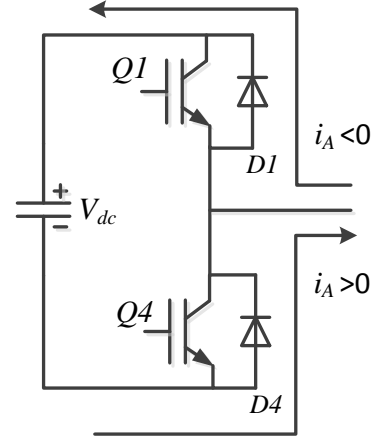

Fig. 3. Configuration of phase A in an inverter.

(a)

(b)

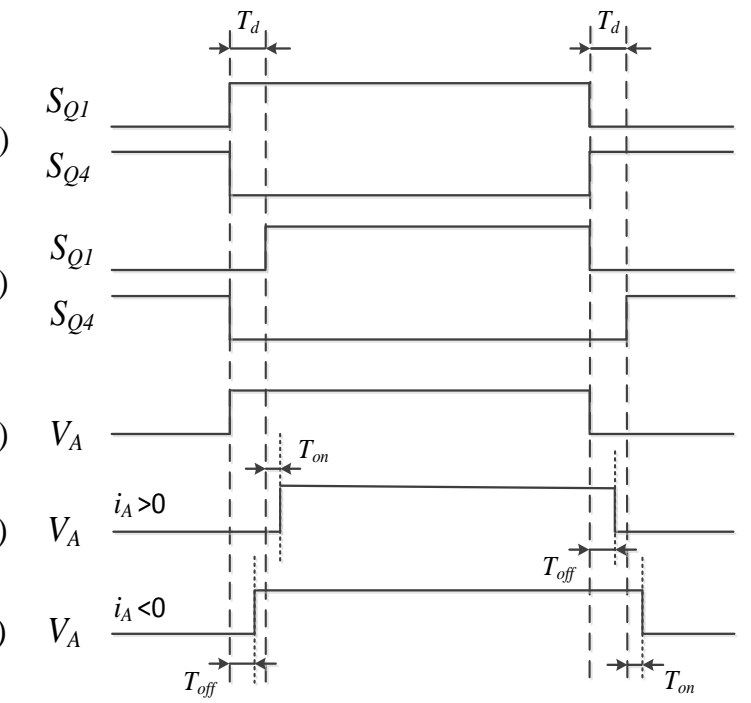

Fig. 4. Gate signals and corresponding output voltages. (a) Commanded gate signal. (b) Actual gate signal including dead-time. (c) Commanded output voltage. (d) Actual output voltage for $i_{A}>0$. (e) Actual output voltage for $i_{A}<0$.

and two zero vectors (000 and 111), can be obtained [15]. The whole plane is evenly divided into six sectors by the nonzero voltage vectors. When given any commanded voltage vector $\boldsymbol{U}_{c}$, two contiguous basic voltage vectors $\boldsymbol{U}_{\boldsymbol{b} \boldsymbol{1}}$ and $\boldsymbol{U}_{b 2}$ are used to feed the motor for $T_{b 1}$ and $T_{b 2}$ respectively to achieve the equivalent effect of $\boldsymbol{U}_{c}$ feeding the motor alone for each PWM period $T_{s}$.

$$
\boldsymbol{U}_{c} \cdot T_{s}=\boldsymbol{U}_{b 1} \cdot T_{b 1}+\boldsymbol{U}_{b 2} \cdot T_{b 2}
$$

As an example, Fig. 2 shows the scenario when the commanded voltage vector $\boldsymbol{U}_{c}$ is in the sector bounded by $\boldsymbol{U}_{4}$ and $\boldsymbol{U}_{6}$.

In this section, only the analysis on phase A is presented, and the results can be extended to the other two phases. The basic configuration of phase A in an inverter is shown in Fig. 3. Fig. 4 gives the commanded gate signal and actual gate signal of phase A as well as the corresponding output voltages they produce. Figs. 4(a) and 4(b) show the commanded gate signal and actual gate signal respectively. Fig. 4(c) shows the commanded output voltage. In practice, IGBTs require short period of time to be turned on and off 


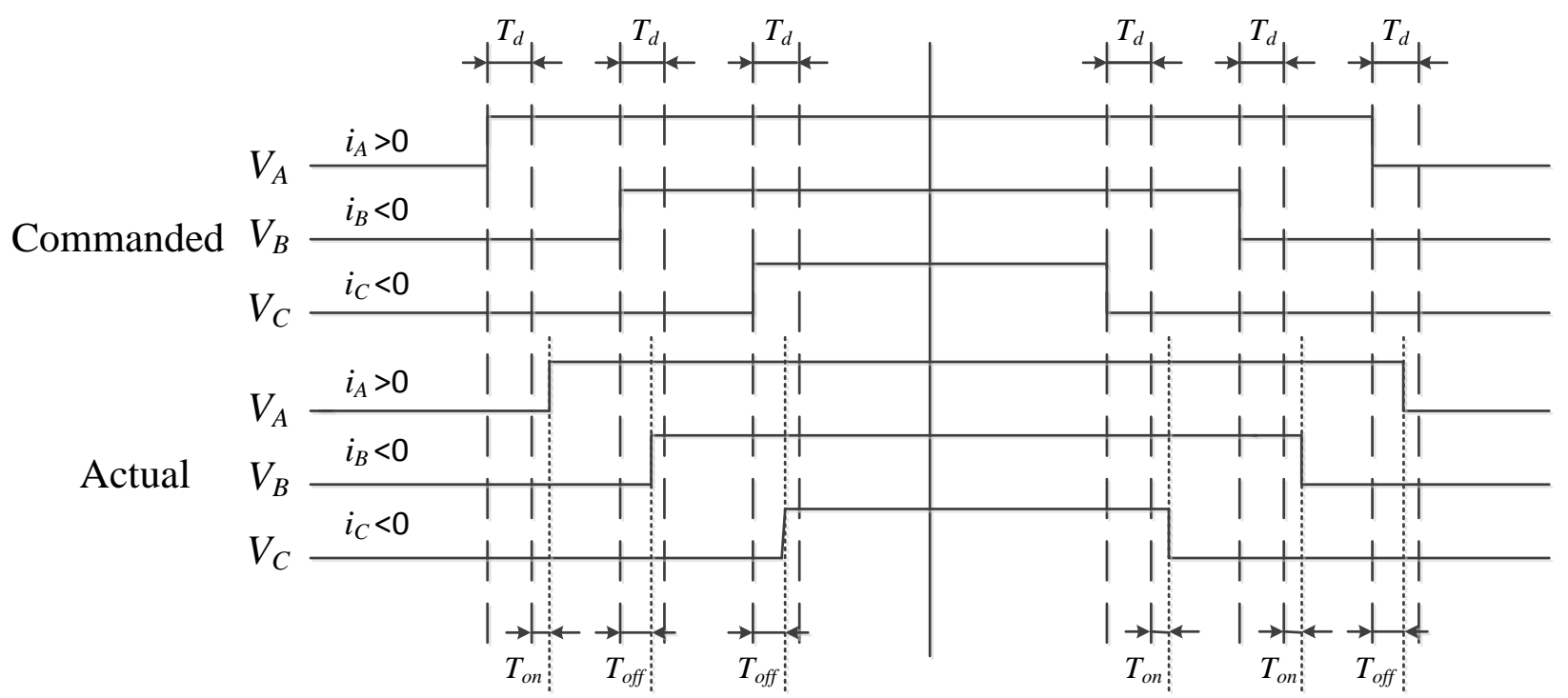

Fig. 5. Commanded voltages and actual voltages.

completely after the switching signals occur, which are denoted as $T_{\text {on }}$ and $T_{\text {off }}$ respectively. For the sake of security, a small length of time that neither one of the two IGBTs conducts during the dead-time inevitably exists. This time is called non-conducting time. During this time, the output voltage is only dependent on the direction of the phase current. For example, when the direction of phase A current is positive, which moves from left to right (Fig. 3), the bottom diode will conduct at the time when both IGBTs are turned off. This phenomenon is caused by the fact that the current direction cannot be changed in such a short time, given the relatively strong inductance of PMSM. Therefore, the output voltage will be negative during the non-conducting time in this situation. Similarly, when the current direction of phase $\mathrm{A}$ is negative, the output voltage is positive during the non-conducting time. Thus, two scenarios of actual output voltage according to the actual gate signal and the direction of the phase current can be determined [Figs. 4(d) and 4(e)]. As a consequence, the actual conducting time of positive output voltage is $T_{d}+T_{\text {on }}-T_{\text {off }}$ shorter (longer) than the commanded conducting time when the direction of the phase current is positive (negative).

The actual output voltage of each phase is altered from the commanded output voltage because of the dead-time. Analyzing the dead-time effect caused by the three phases becomes more complicated. As an example, Fig. 5 shows a comparison between commanded output voltages and actual output voltages, where the current of phase $\mathrm{A}$ is positive and the currents of phases $\mathrm{B}$ and $\mathrm{C}$ are negative. The commanded voltage vector $\boldsymbol{U}_{\boldsymbol{c}}$ is located in Sector 1 , which is bounded by $\boldsymbol{U}_{4}$ and $\boldsymbol{U}_{6}$. Given that the currents of phases $\mathrm{B}$ and $\mathrm{C}$ are negative, both of their positive output voltages are elongated. Therefore, actual $T_{6}$ is equal to commanded $T_{6}$. Meanwhile, given that the direction of the current of phase $\mathrm{A}$ is positive,

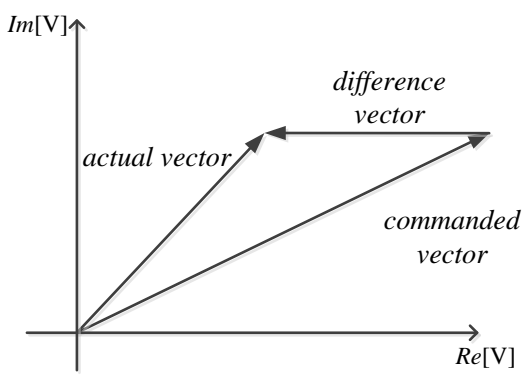

Fig. 6. Relationship between commanded voltage vector and actual voltage vector only considering dead-time effect.

its positive output voltage is contracted. Thus, actual $T_{4}$ is $2\left(T_{d}+T_{\text {on }}-T_{\text {off }}\right)$ shorter than commanded $T_{4}$. Here, $\Delta T$ is introduced to denote $2\left(T_{d}+T_{\text {on }}-T_{\text {off }}\right)$. In this case, the adverse effect of the dead-time is that $T_{4}$ is contracted by $\Delta T$. Therefore, the difference between actual voltage vector and commanded voltage vector is $-\Delta T \cdot \boldsymbol{U}_{4}$ (Fig. 6). However, the commanded voltage vector and the current directions vary with time. Thus, the adverse effect caused by the dead time changes frequently. In this paper, difference vector is defined as the difference between actual voltage vector and commanded voltage vector. To further analyze the difference vector caused by the dead-time, the plane in Fig. 1 is again evenly divided into six parts according to the different combinations of phase current directions (Fig. 7 and Table I). The vector equation of the PMSM can be expressed as follows:

$$
\boldsymbol{U}_{s}=R_{s} \boldsymbol{I}_{s}+\frac{\mathrm{d} \boldsymbol{\Psi}_{s s}}{\mathrm{~d} t}+j \omega \boldsymbol{\Psi}_{f}
$$

where

$$
\frac{\mathrm{d} \boldsymbol{\Psi}_{s s}}{\mathrm{~d} t}=\frac{\mathrm{d} \Psi_{s s}}{\mathrm{~d} t} e^{j \theta_{s s}}+j \frac{\mathrm{d} \theta_{s s}}{\mathrm{~d} t} \boldsymbol{\Psi}_{s s}
$$




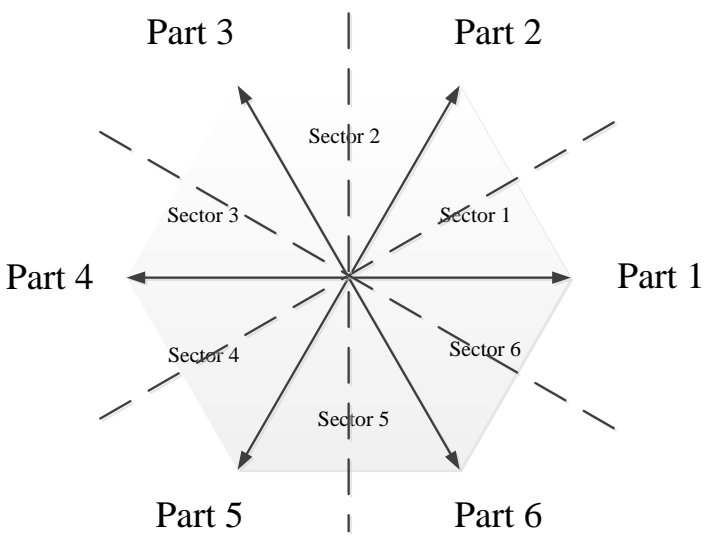

Fig. 7. Six parts according to the different combinations of phase currents directions.

TABLE I

Parts ANd CoRresponding Difference Vectors CAUSED By DifFerent Combinations of Phase CuRrent Directions

\begin{tabular}{c|c|c|c|c}
\hline Part & $i_{A}$ & $i_{B}$ & $i_{C}$ & $\begin{array}{c}\text { Difference vector } \\
\text { under steady state }\end{array}$ \\
\hline 1 & $>0$ & $<0$ & $<0$ & $-\Delta T \cdot \boldsymbol{U}_{4}$ \\
\hline 2 & $>0$ & $>0$ & $<0$ & $-\Delta T \cdot \boldsymbol{U}_{6}$ \\
\hline 3 & $<0$ & $>0$ & $<0$ & $-\Delta T \cdot \boldsymbol{U}_{2}$ \\
\hline 4 & $<0$ & $>0$ & $>0$ & $-\Delta T \cdot \boldsymbol{U}_{3}$ \\
\hline 5 & $<0$ & $<0$ & $>0$ & $-\Delta T \cdot \boldsymbol{U}_{1}$ \\
\hline 6 & $>0$ & $<0$ & $>0$ & $-\Delta T \cdot \boldsymbol{U}_{5}$ \\
\hline
\end{tabular}

where $\boldsymbol{U}_{s}$ is the stator voltage vector, $R_{s}$ is the stator resistance, $\boldsymbol{I}_{\boldsymbol{s}}$ is the stator current vector, $\boldsymbol{\Psi}_{\text {ss }}$ is the stator self-induced flux linkage vector with a modulus of $\Psi_{s s}, \theta_{s s}$ is the vector angle of $\boldsymbol{\Psi}_{s s}, j$ is the complex operator, $\omega$ is the electric angular speed, and $\boldsymbol{\Psi}_{f}$ is the flux linkage vector established by magnets. The vector angle of $\boldsymbol{U}_{\boldsymbol{s}}$ can be different from that of $\boldsymbol{I}_{\boldsymbol{s}}$ because of the variation of system state and control strategy. In most industrial cases, especially the ones with surface-mounted PMSM, the goal is to control the current of $d$-axis to zero, which makes $\boldsymbol{I}_{s} \pi / 2$ phase angle ahead of $\boldsymbol{\Psi}_{f}$. Therefore, under such kind of control strategy, the difference between the vector angle of $\boldsymbol{U}_{\boldsymbol{s}}$ and that of $\boldsymbol{I}_{\boldsymbol{s}}$ can be small in the steady state, given that $\frac{\mathrm{d} \boldsymbol{\Psi}_{s s}}{\mathrm{~d} t}$ is much smaller than $R_{s} \boldsymbol{I}_{s}+j \omega \boldsymbol{\Psi}_{f}$ in Eq. (2). As a result, when the motor is operating at steady state, based on the similar analysis of the example in Fig.5, the difference vectors can be sorted into six different cases due to the six different parts in which $\boldsymbol{I}_{\boldsymbol{s}}$ locates (Table I).

According to the principle of field-oriented control strategy, $d q$ rotor reference frame is rotating at the same speed with the rotor, and the $d$-axis is aligned with $\boldsymbol{\Psi}_{f}$. Within one rotation

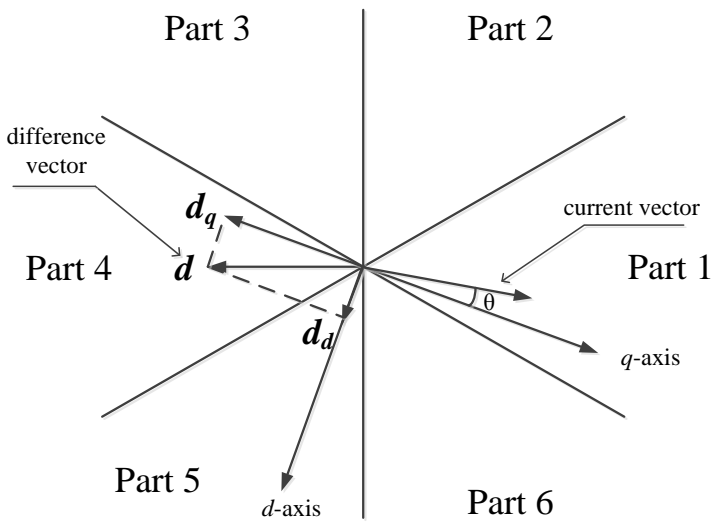

Fig. 8. Case of current vector locating in Part 1 and its corresponding difference vector.

cycle, the difference vector changes six times because of the six different parts that the current vector passes. For each part where the current vector locates in, the corresponding difference vector $\boldsymbol{d}$ can be decomposed into two separate vectors $\boldsymbol{d}_{\boldsymbol{d}}$ and $\boldsymbol{d}_{\boldsymbol{q}}$ imposed on the $d q$ axes respectively(Fig. 8). To obtain detailed information about $\boldsymbol{d}_{\boldsymbol{d}}$ and $\boldsymbol{d}_{\boldsymbol{q}}$ during one entire rotation cycle, the case of the current vector locating in Part 1 , is analyzed in this section as an example. The results can be extended to other scenarios. Here, the rotating direction is assumed to be counterclockwise (Fig. 8). When the current vector first passes the lower boundary of Part 1 at time $t_{1}$, the difference vector switches to $-\Delta T \cdot U_{4}$, whose modulus is denoted as $d$. As long as the current vector is in Part $1, d_{d}$ and $d_{q}$, which are the modulus of $\boldsymbol{d}_{\boldsymbol{d}}$ and $\boldsymbol{d}_{\boldsymbol{q}}$ respectively, can be calculated from the following equations:

$$
\begin{aligned}
& d_{d}=d \cdot \cos \left[\omega\left(t-t_{1}\right)+\frac{\pi}{3}-\theta\right] \\
& d_{q}=-d \cdot \sin \left[\omega\left(t-t_{1}\right)+\frac{\pi}{3}-\theta\right]
\end{aligned}
$$

Given that all difference vectors have identical modulus $d$ and the six parts as well as their corresponding difference vectors are distributed evenly and symmetrically in the plane, the same equations as that of Part 1 can be deduced for the other five parts. Therefore, when the system is in the steady state, $d_{d}$ and $d_{q}$ are periodic variables, whose angular frequency is six times of $\omega$. This kind of disturbance with speed-varying frequency deteriorates the performance of current tracking, which eventually causes the torque ripple.

\section{COMPENSATION OF DEAD-TIME EFFECT}

In this section, a control scheme using two linear ESOs is proposed to compensate for the dead-time effect. The proposed control scheme is based on the active disturbance rejection control strategy. Its objective is to make the output (actual current vector) behave as desired by designing a proper input (commanded voltage vector), which contains the 
negative estimate of disturbance (here, caused by the dead-time). Therefore, the adverse effect brought by the disturbance is counteracted by the negative estimate of disturbance in the designed input. Details of the proposed method are provided below.

\section{A. Mathematic Model of PMSM Considering Dead-Time Effect}

Based on the previous analysis in this paper, the mathematical model of PMSM considering the difference vector caused by the dead-time can be expressed as follows:

$$
\boldsymbol{U}_{c}+\boldsymbol{d}=R_{s} \boldsymbol{I}_{s}+\frac{\mathrm{d} \boldsymbol{\Psi}_{s s}}{\mathrm{~d} t}+j \omega \boldsymbol{\Psi}_{f}
$$

Decomposing Eq. (6) into the $d q$ rotor reference frame leads to the following equations:

$$
\begin{gathered}
U_{c d}+d_{d}=R_{s} i_{d}+L_{d} \frac{\mathrm{d} i_{d}}{\mathrm{~d} t}-\omega L_{q} i_{q} \\
U_{c q}+d_{q}=R_{s} i_{q}+L_{q} \frac{\mathrm{d} i_{q}}{\mathrm{~d} t}+\omega\left(L_{d} i_{d}+\Psi_{f}\right)
\end{gathered}
$$

where $U_{c d}$ and $U_{c q}$ are the commanded voltages, $L_{d}$ and $L_{q}$ are the inductances, and $i_{d}, i_{q}$ are the actual currents of $d q$ axes. $\Psi_{f}$ is the modulus of $\boldsymbol{\Psi}_{f}$. In practice, $U_{c d}$ and $U_{c q}$ are determined by the current controllers of $d q$ axes. Meanwhile, $d_{d}$ and $d_{q}$ are periodic disturbances caused by the dead time.

\section{B. Design of Current Controller Using ESO}

In this section, only the details of designing $d$-axis current controller are presented. The controller of $q$-axis can also be achieved through a similar method. To design the ESO, Eq. (7) is rearranged as follows:

$$
\frac{\mathrm{d} i_{d}}{\mathrm{~d} t}=\frac{\omega L_{q} i_{q}}{L_{d}}-\frac{R_{s} i_{d}}{L_{d}}+\frac{d_{d}}{L_{d}}+\frac{U_{c d}}{L_{d}}
$$

In practice, obtaining an accurate $L_{d}$ by measurement is difficult. Furthermore, the value of $L_{d}$ varies with operation conditions. Here, the measured value of $L_{d}$ is denoted as $L_{m}$, and the difference between $\frac{1}{L_{d}}$ and $\frac{1}{L_{m}}$ is denoted as $\Delta$. Then, Eq. (9) can be rewritten as the following equation by replacing the fourth element on the right side with $\left(\frac{1}{L_{m}}+\Delta\right) U_{c d}:$

$$
\frac{\mathrm{d} i_{d}}{\mathrm{~d} t}=\frac{\omega L_{q} i_{q}}{L_{d}}-\frac{R_{s} i_{d}}{L_{d}}+\frac{d_{d}}{L_{d}}+U_{c d} \cdot \Delta+\frac{U_{c d}}{L_{m}}
$$

Then, a new variable $D_{d}$ is introduced to denote $\frac{\omega L_{q} i_{q}}{L_{d}}-\frac{R_{s} i_{d}}{L_{d}}+\frac{d_{d}}{L_{d}}+U_{c d} \cdot \Delta$, which is regarded as the lumped disturbance on $d$-axis. Thus, Eq. (10) can be simplified into the following equation:

$$
\frac{\mathrm{d} i_{d}}{\mathrm{~d} t}=D_{d}+\frac{U_{c d}}{L_{m}}
$$

Considering $\dot{D}_{d}=a$, an extended state system can then be constructed as follows:

$$
\left\{\begin{array}{c}
\frac{\mathrm{d} i_{d}}{\mathrm{~d} t}=D_{d}+\frac{U_{c d}}{L_{m}} \\
\dot{D}_{d}=a
\end{array}\right.
$$

Therefore, a linear ESO, which is easy to implement and only needs a small source of computation, can be designed as follows [16]-[17]:

$$
\left\{\begin{array}{c}
\dot{z}_{1}=z_{2}-2 p\left(z_{1}-i_{d}\right)+\frac{U_{c d}}{L_{m}} \\
\dot{z}_{2}=-p^{2}\left(z_{1}-i_{d}\right)
\end{array}\right.
$$

where $-p$ is the desired double poles of ESO, $z_{1}$ is the estimate of $i_{d}$, and $z_{2}$ is the estimate of $D_{d}$. When $-p$ is set large enough, $z_{2}$ can track $D_{d}$ fast enough [18]-[19]. However, the noise involved in the detected currents can be amplified dramatically through the ESO when the pole is set too far from the origin. Therefore, $-p$ is required to be set in an appropriate range in practical implementation.

According to the disturbance rejection control strategy, the input $U_{c d}$ can be designed as follows:

$$
U_{c d}=K_{d}\left(i_{r d}-i_{d}\right)-Z_{2} \cdot L_{m}
$$

where $K_{d}$ is the adjustable coefficient, and $i_{r d}$ is the reference current of $d$-axis. Substituting $U_{c d}$ in Eq. (11) with Eq. (14) yields the following equation:

$$
\frac{\mathrm{d} i_{d}}{\mathrm{~d} t}=D_{d}-z_{2}+\frac{K_{d}\left(i_{r d}-i_{d}\right)}{L_{m}}
$$

Notably, the lumped disturbance $D_{d}$ will be compensated remarkably when $z_{2}$ tracks $D_{d}$ fast enough, which makes the whole system a first-order integral-chain system as follows:

$$
\frac{\mathrm{d} i_{d}}{\mathrm{~d} t}=\frac{K_{d}\left(i_{r d}-i_{d}\right)}{L_{m}}
$$

The transfer function between $i_{r d}$ and $i_{d}$ can be written as follows:

$$
i_{d}(s)=\frac{1}{\frac{L_{m}}{K_{d}} s+1} i_{r d}(s)
$$

Consequently, the system between $i_{r d}$ and $i_{d}$ is equivalent to an inertial system with time constant of $L_{m} / K_{d}$ when $D_{d}$ is compensated. Therefore, the relatively high frequency disturbance caused by the dead-time along with other uncertainties, which deteriorate the performance of current tracking, is inhibited by the compensation of $D_{d}$.

A similar result can be acquired by introducing a new variable $D_{q}$ for $q$-axis, which is also estimated through the ESO. The block diagram of the proposed current control scheme is shown in Fig. 9.

\section{SIMULATIONS AND EXPERIMENTS}

In this section, simulations and experiments were conducted on an eight-pole PMSM to verify the effectiveness of the proposed compensation method. 


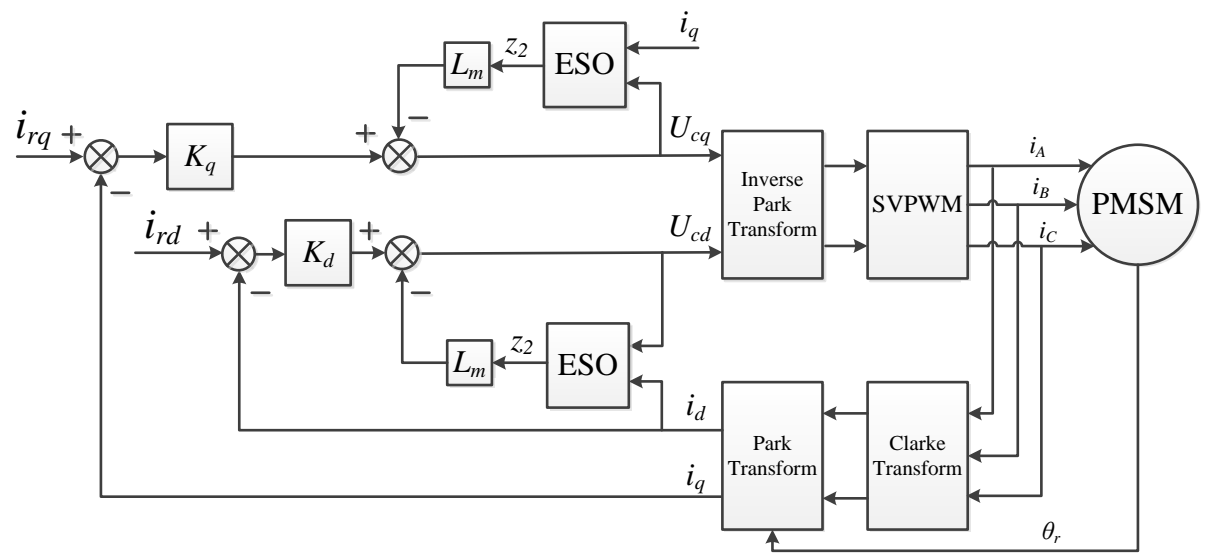

Fig. 9. Block diagram of the PMSM driving system.

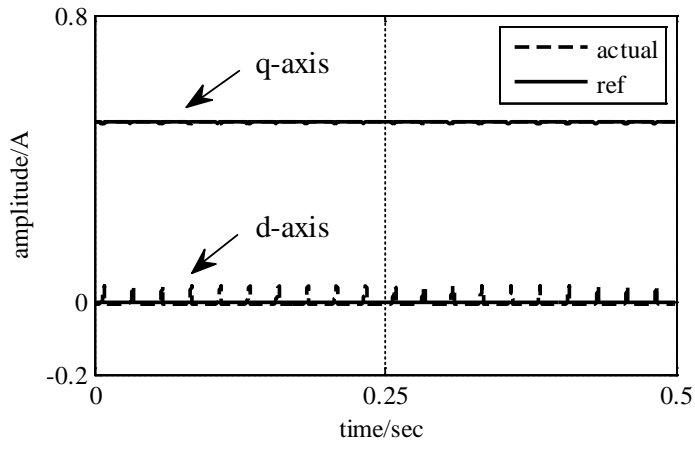

(a)

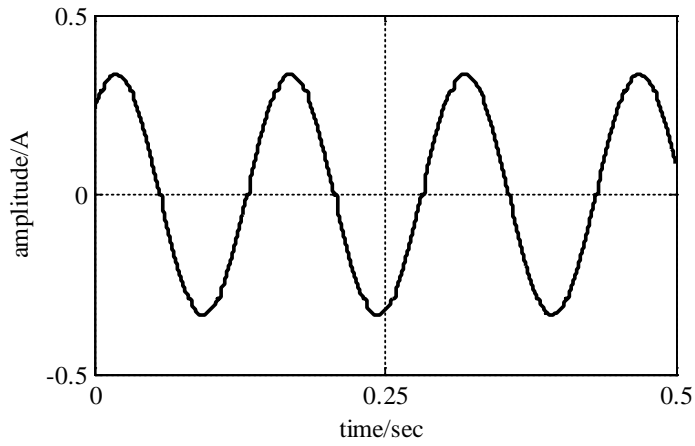

(c)

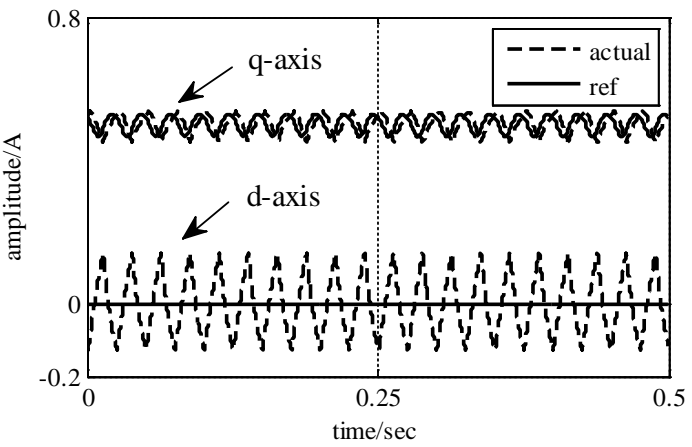

(b)

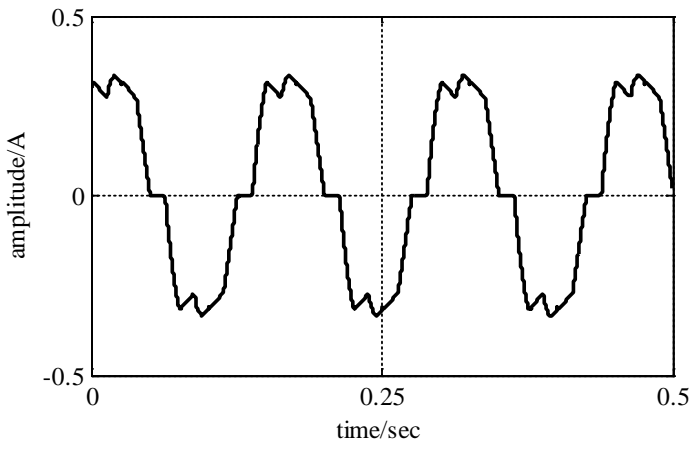

(d)

Fig. 10. Simulated waveforms of $d q$ axes and phase currents at $100 \mathrm{rpm}$. (a) Waveforms of $d q$ axes currents with proposed method. (b) Waveforms of $d q$ axes currents with PI controller. (c) Waveform of phase current with proposed method. (d) Waveform of phase current with PI controller.

\section{A. Simulations}

Figs. 10(a) and 10(b) show the tracking performance of $d q$ axes currents with the proposed control scheme and PI controller respectively. The reference of $q$-axis current is given by the speed PI controller and the reference of $d$-axis is set to zero for both methods. Given the disturbance caused by the dead time, harmonics significantly exist in the $d q$ axes currents with PI controller, which deteriorate the tracking performance. When compared with the PI controller, the harmonics of $d q$ axes currents are reduced remarkably with the proposed control scheme based on its stronger ability of disturbance rejection, which improves the tracking performance. In addition, Figs. 10(c) and 10(d) provide waveforms of phase current with the proposed control scheme and the PI controller respectively. The phase current with the PI controller is severely distorted by the dead-time, whereas the phase current with the proposed control scheme is much closer to the normal sinusoid.

Fig. 11 shows the spectra of $d q$ axes currents with the proposed control scheme and PI controller. The main component of harmonic caused by dead-time is the sixth-order harmonics, whose angular frequency is six times of $\omega$, which matches the former analysis [Figs. 11(b) and 11(d)]. By contrast, the sixth-order harmonics caused by the dead-time considerably decreased with the proposed control scheme [Figs. 11(a) and 11(c)]. 


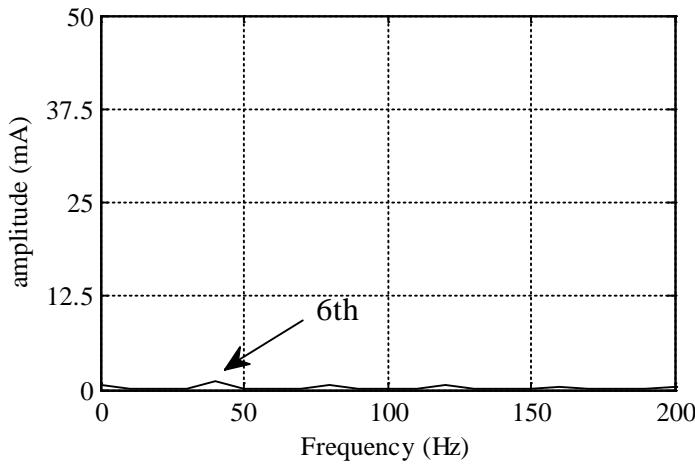

(a)

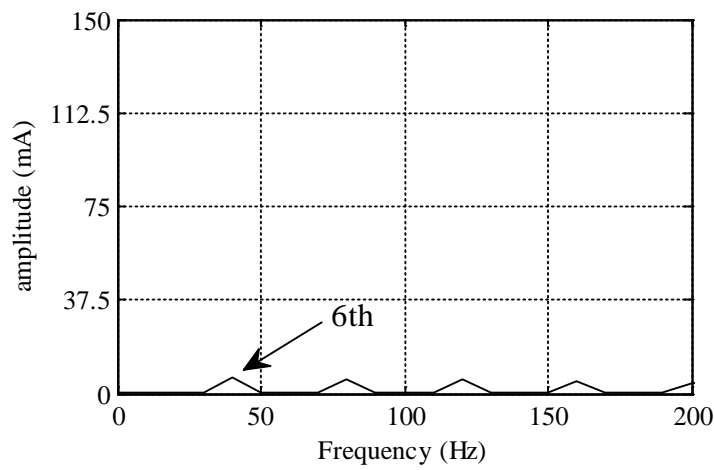

(c)

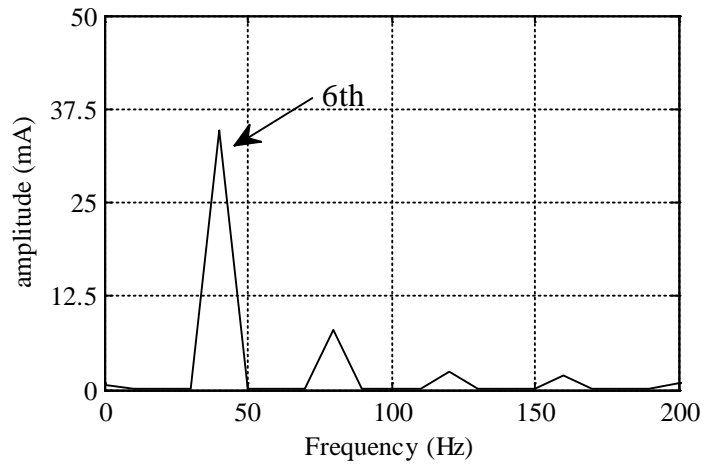

(b)

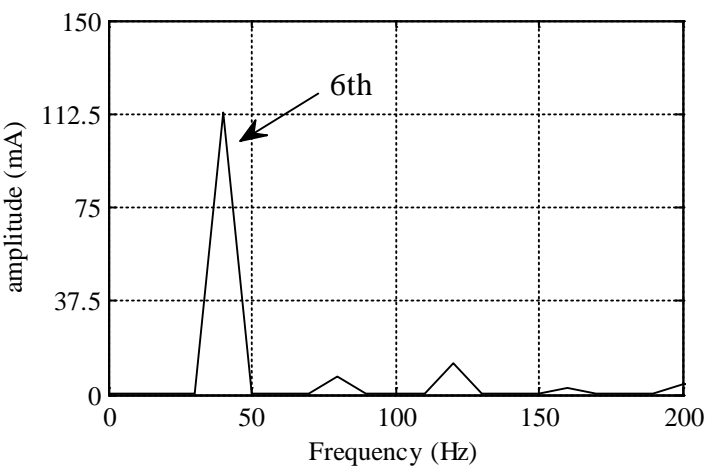

(d)

Fig. 11. Simulated spectra of $d q$ axes currents at $100 \mathrm{rpm}$. (a) Spectrum of $i_{q}$ with the proposed method. (b) Spectrum of $i_{q}$ with the PI controller. (c) Spectrum of $i_{d}$ with the proposed method. (d) Spectrum of $i_{d}$ with the PI controller.

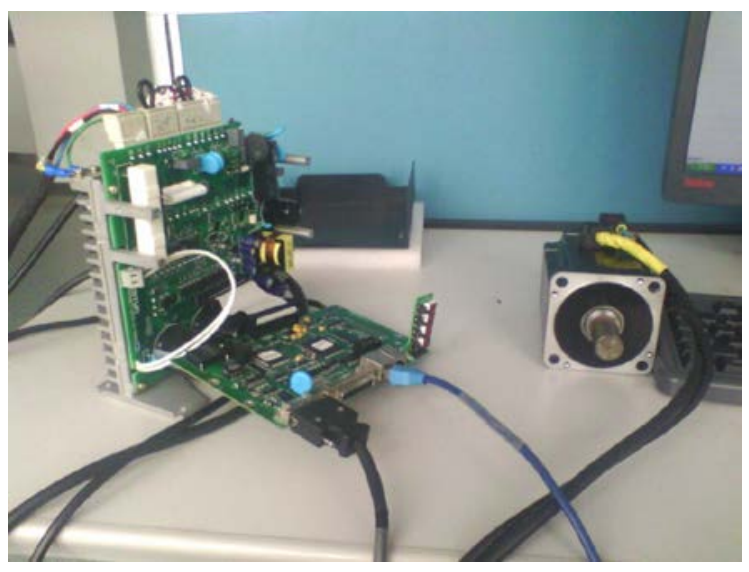

Fig. 12. Tested PMSM drive system.

\section{B. Experiments}

Fig. 12 shows the structure of the tested PMSM drive system. The processor of the tested drive system is a fixed-point DSP (TMS3202812) with a clock frequency of $150 \mathrm{MHz}$. The DC link voltage is $310 \mathrm{~V}$, and phase currents are measured by Hall-effect devices. An absolute encoder is employed to obtain the rotating speed and the position information of the rotor. The PWM period is set as $100 \mu \mathrm{s}$, and the dead-time is set as $3.2 \mu \mathrm{s}$. The parameters of the tested motor are shown in Table II.
TABLE II

Parameters of Tested Motor

\begin{tabular}{lc|lc}
\hline power rating & $750[\mathrm{~W}]$ & rated voltage & $200[\mathrm{~V}]$ \\
\hline rated torque & $2.39[\mathrm{Nm}]$ & rated speed & $3000[\mathrm{rpm}]$ \\
\hline rated current & $4[\mathrm{~A}]$ & Linkage flux & $0.0931[\mathrm{~Wb}]$ \\
\hline stator resistance & $1[\Omega]$ & Pole pairs & 4 \\
\hline
\end{tabular}

The performance of the proposed control scheme is compared with that of the commonly used PI controller. In industrial applications, the reference current of $q$-axis is usually given by the speed controller, whereas the reference current of $d$-axis is set to zero in most cases, especially for surface-mounted PMSM. Hence, in the experiments of this paper, a speed PI controller is employed to obtain the reference current of $q$-axis for both the proposed control scheme and the PI controller. The reference current of $d$-axis is set to zero for all the cases in this paper. The motor operates without load to avoid the possible uncertainties introduced by the load actuator. Fig. 13 presents the performances of current tracking in the steady state under different operation speeds. The solid lines are the reference currents of $d q$ axes, and the dashed lines are the actual currents of $d q$ axes. When the system operates at a relatively low speed such as $50 \mathrm{rpm}$ or $100 \mathrm{rpm}$ [Figs. 13(a), 13(b), 13(c), and 13(d)], the currents of both $d q$ axes fail to follow 


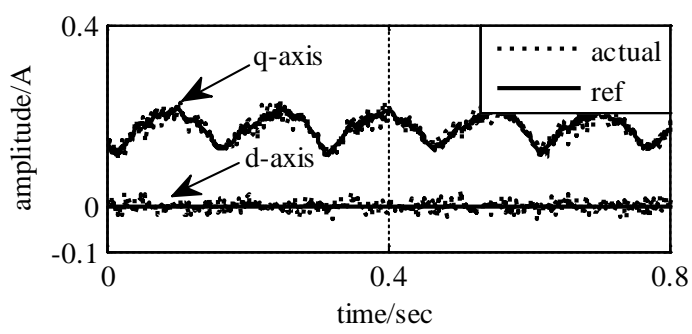

(a)

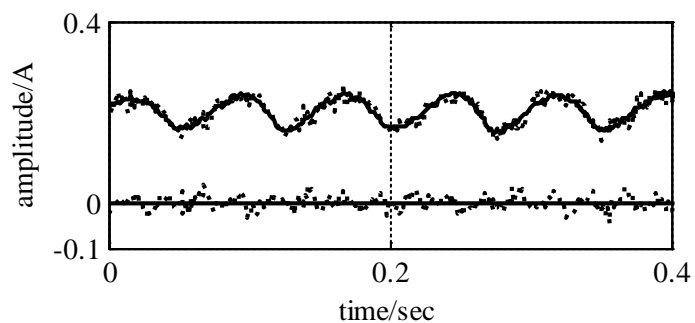

(c)

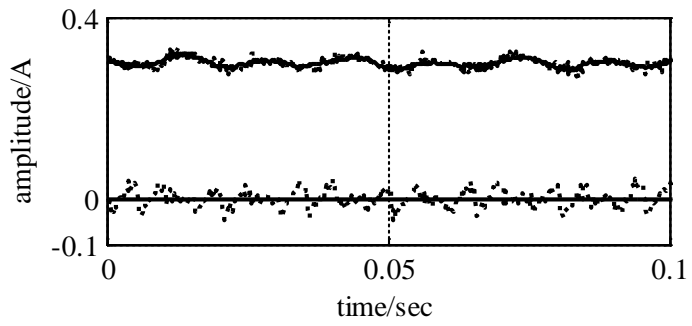

(e)

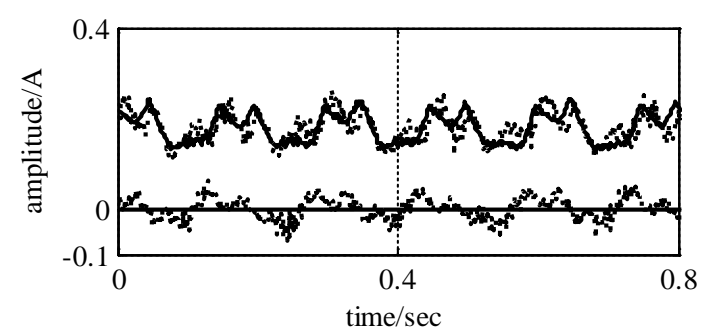

(b)

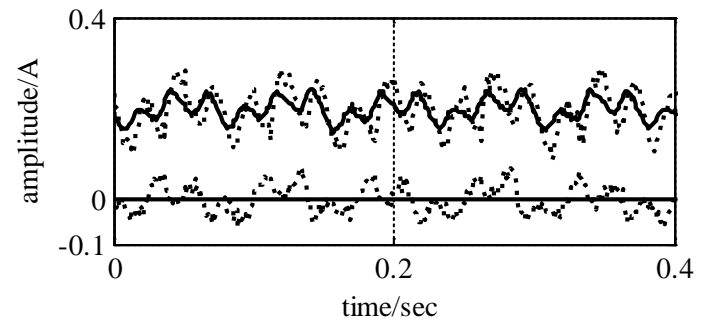

(d)

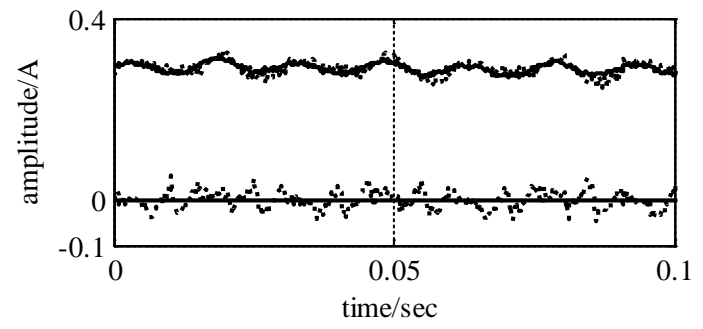

(f)

Fig. 13. Current tracking performance at different operation speeds. (a) Case of $50 \mathrm{rpm}$ with the proposed control scheme. (b) Case of 50 rpm with PI controller. (c) Case of 100 rpm with the proposed control scheme. (d) Case of 100 rpm with PI controller. (e) Case of 500 rpm with the proposed control scheme. (f) Case of 500 rpm with PI controller.

the reference currents close with the current PI controller because of the disturbance caused by the dead-time. By contrast, the performance of current tracking is remarkably improved with the proposed control scheme because of its stronger ability of disturbance rejection. The following comparison can be acquired by analyzing the spectra of $d q$ currents in the steady state. Figs. 14 and 15 show the spectra of $d q$ currents with operation speeds at 50 and $100 \mathrm{rpm}$ respectively. Here, the electric angle frequency is defined as fundamental frequency. The sixth-order harmonics of $d q$ currents with PI controller are significant at relatively low operation speed, whereas that of $d q$ currents are much smaller with the proposed control scheme. This phenomenon matches the analysis that the disturbances caused by the dead-time on $d q$ axes are six times the frequency of the electrical angle. Moreover, this comparison also shows the proposed control scheme has good ability to compensate for the dead-time effect. It should be pointed out that the tested motor exhibits being disturbed eight times by mechanical resistance during each rotation cycle of the rotor, which results in the second-order harmonics of the rotor speed. Then this signal of two times the fundamental frequency is passed to the reference current of $q$-axis by the speed PI controller. As a consequence, the current of $q$-axis acquires the 2nd order harmonics by tracking the reference current. Significant second-order harmonics are observed in the $q$-axis current for both the proposed control scheme and the PI controller [Figs. 14(c), 14(d), 15(c), and 15(d).

Meanwhile, the adverse effects caused by the dead-time become much smaller when the operation speed increases to a certain level. As shown in Fig. 13(f), the performance of the current tracking with PI controller at $500 \mathrm{rpm}$ is much better than that of Figs. 13(b) and 13(d). This phenomenon is based on Eqs. (7) and (8), where the PMSM behaves as two inertia elements of $d q$ axes. Therefore, the PMSM can be regarded as two low-pass filters, whose cut-off frequency is determined by the inductance and resistance of the stator. According to the analysis, the disturbances $d_{d}$ and $d_{q}$ are six times the frequency of $\omega$, which means their frequency can increase dramatically when the motor speeds up. Thereby, $d_{d}$ and $d_{q}$ are filtered by the PMSM itself at relatively high operation speed, where the frequency of $d_{d}$ and $d_{q}$ exceeds the cut-off frequency. This is the reason that dead-time effects mainly occur at relatively low operation speed range. Fig. 16 shows the spectra of $d q$ currents at $500 \mathrm{rpm}$. The sixth-order harmonics (200 Hz at $500 \mathrm{rpm}$ ) in each sub-graph is negligibly small at this speed, which matches the analysis that the disturbances caused by dead time are filtered by the 


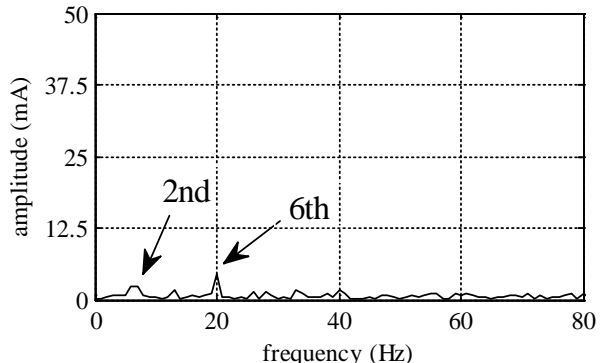

(a)

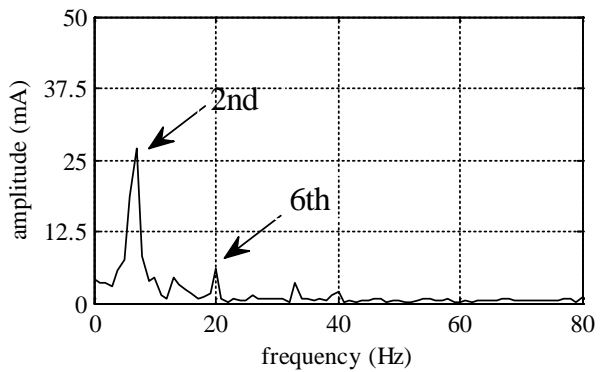

(c)

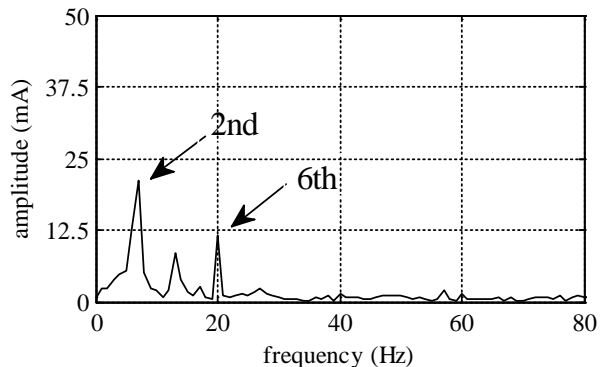

(b)

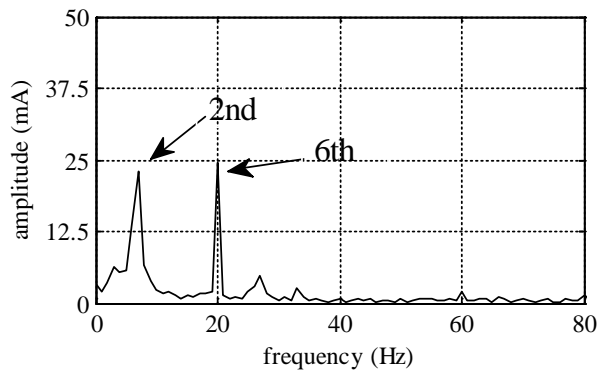

(d)

Fig. 14. Comparison of current spectrum with operation speed at $50 \mathrm{rpm}$. (a) Spectrum of $i_{d}$ with the proposed control scheme. (b) Spectrum of $i_{d}$ with the PI controller. (c) Spectrum of $i_{q}$ with the proposed control scheme. (d) Spectrum of $i_{q}$ with the PI controller.

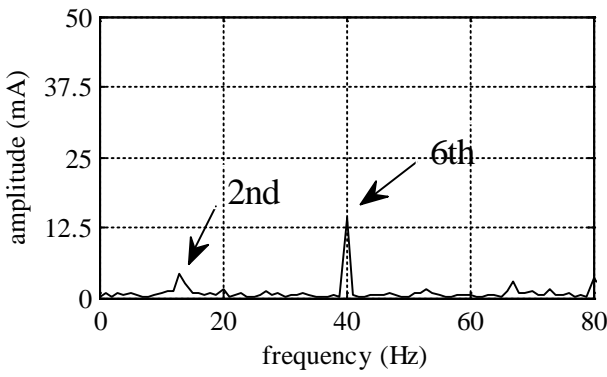

(a)

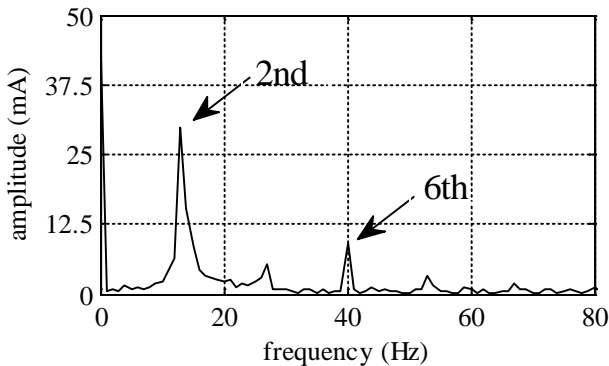

(c)

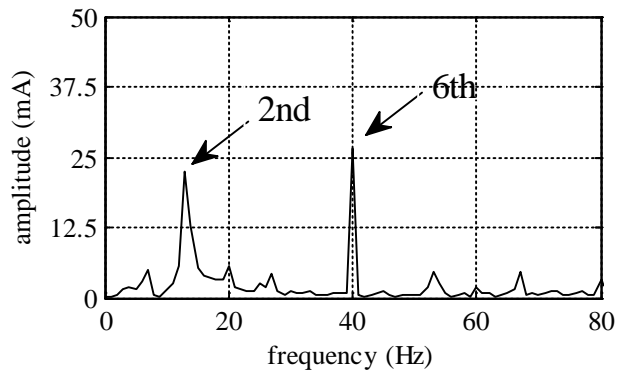

(b)

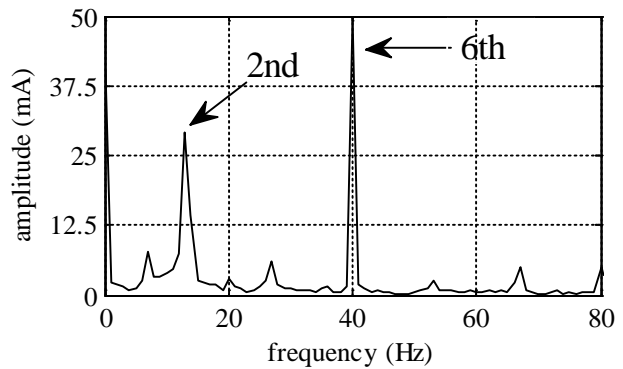

(d)

Fig. 15. Comparison of current spectrum with operation speed at 100rpm. (a) Spectrum of $i_{d}$ with proposed control scheme. (b) Spectrum of $i_{d}$ with the PI controller. (c) Spectrum of $i_{q}$ with the proposed control scheme. (d) Spectrum of $i_{q}$ with the PI controller.

PMSM itself at relatively high speed. The harmonics with frequencies of 130,270 , and $400 \mathrm{~Hz}$, which exist for both the proposed controller and the PI controller at this operation speed, result from the noise introduced by the hardware and sampling.

As generally accepted, three normally sinusoidal phase currents with $2 \pi / 3$ phase angle difference among each other are the prerequisite for outputting constant electromagnetic torque for a perfectly designed three-phase PMSM. In addition, the distortion of the phase currents, which results in the ripples of electromagnetic torque, is caused by their harmonics. Based on the previous analysis, the dead-time effect can cause the sixth-order harmonics of $d q$ currents, which change into the corresponding harmonics of phase currents after coordinate transform and distort the waveforms of phase currents. Thus, the waveforms of phase currents are displayed in Fig. 17 to show a straightforward comparison

between the proposed control scheme and the PI controller. In the cases of low speed range [Figs. 17(a), 17(b), 17(c), and 17(d)], the waveforms of phase current with the PI controller 


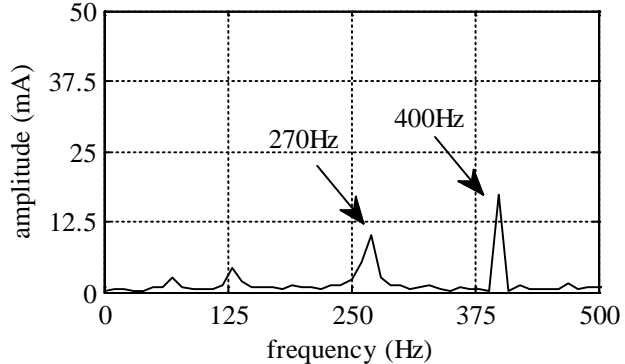

(a)

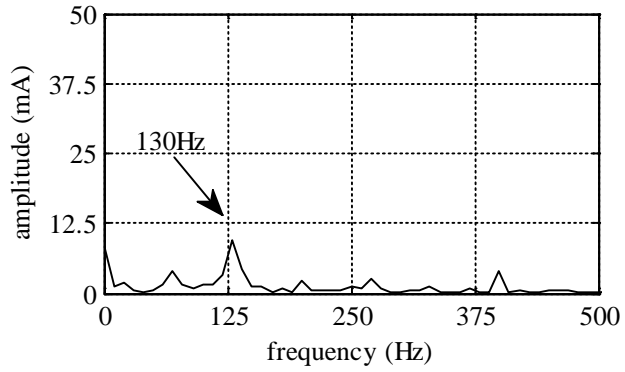

(c)

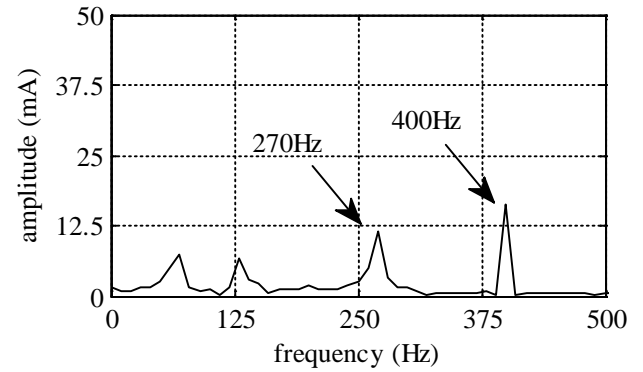

(b)

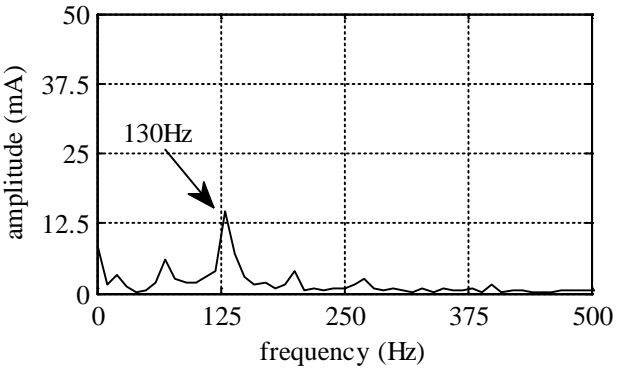

(d)

Fig. 16. Comparison of current spectrum with operation speed at $500 \mathrm{rpm}$. (a) Spectrum of $i_{d}$ with the proposed control scheme. (b) Spectrum of $i_{d}$ with the PI controller. (c) Spectrum of $i_{q}$ with the proposed control scheme. (d) Spectrum of $i_{q}$ with the PI controller.

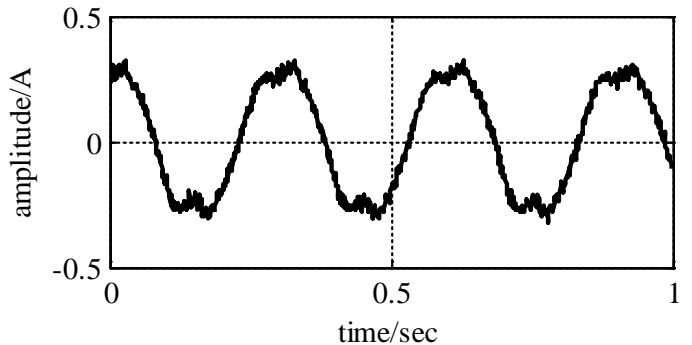

(a)

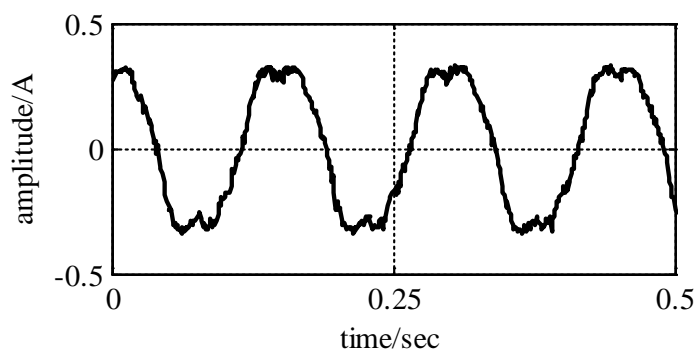

(c)

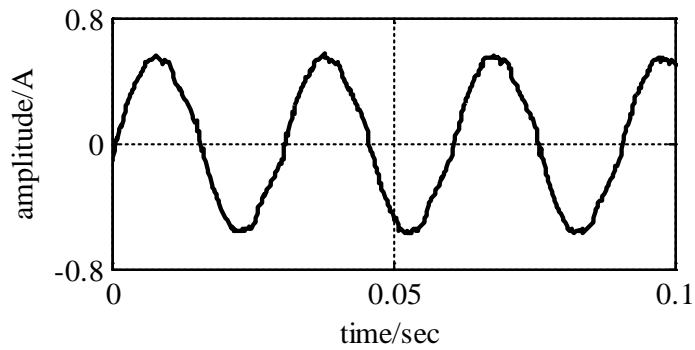

(e)

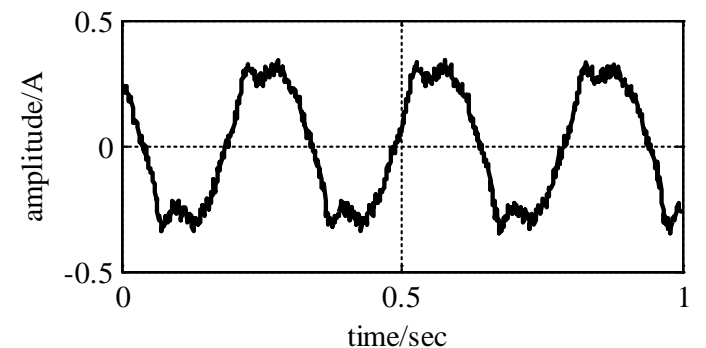

(b)

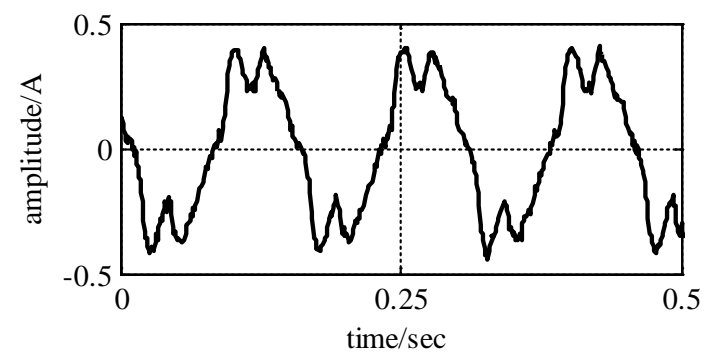

(d)

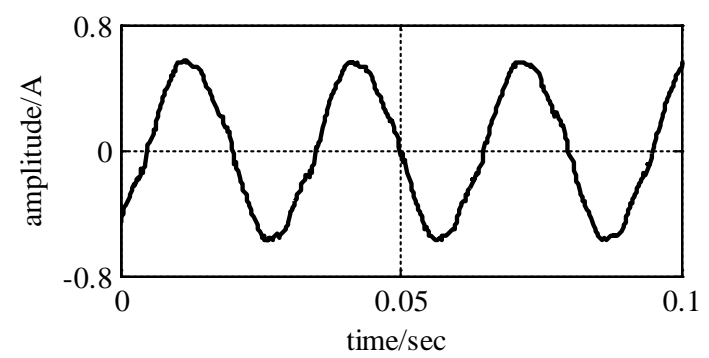

(f)

Fig. 17. Phase currents at different operation speeds. (a) Phase currents at 50 rpm with the proposed control scheme. (b) Phase currents at 50 rpm with the PI controller. (c) Phase currents at $100 \mathrm{rpm}$ with the proposed control scheme. (d) Phase currents at $100 \mathrm{rpm}$ with the PI controller. (e) Phase currents at 500 rpm with the proposed control scheme. (f) Phase currents at 500 rpm with the PI controller. 
are severely distorted because of the harmonics, whereas the waveforms with the proposed control scheme are much closer to normal sinusoid. However, these waveforms are incompletely sinusoidal because of the existence of harmonics introduced by the mechanical resistance. In the cases of relatively high operation speed [Figs. 17(e) and 17(f)], the phase current waveforms with both of the proposed method and the PI controller are close to normal sinusoid. This phenomenon is because that the PMSM itself inhibits the adverse effects caused by the dead-time at high speed range. All of these experimental results accord with the analysis provided in this paper.

\section{CONCLUSION}

A detailed analysis of dead-time effect is presented in this paper. Based on the analysis, the dead-time causes two periodic disturbances $d_{d}$ and $d_{q}$ with six times the frequency of electric angle on $d q$ axes respectively. These relatively high-frequency disturbances result in the degeneration of current tracking performance and the distortion of phase currents. To compensate for these adverse effects, a current control scheme using two linear ESOs are proposed. The ESOs can track the disturbances fast enough when the poles are set into proper range. Therefore, the commanded voltages given by the proposed current control scheme contain the negative estimates of the disturbances, which counteract the real disturbances and improve the performance of current tracking. Simulations and experiments are carried out on a 8-pole PMSM to verify the effectiveness of the proposed current control scheme and the analysis in this paper.

\section{ACKNOWLEDGMENT}

This work was supported by the Science Foundation for Distinguished Young Scholars of Jiangsu Province under Grant BK20130018 and the High-level Talents Program in Six Industries of Jiangsu Province under Grant DZXX-30.

\section{REFERENCES}

[1] J. W. Choi and S. K. Sul, "A new compensation strategy reducing voltage/current distortion in PWM VSI systems operating with low output voltage," IEEE Trans. Ind. Applicat., Vol. 27, No. 5, pp. 552-559, May 1991.

[2] S.-H. Hwang and J.-M. Kim, "Dead time compensation method for voltage-fed PWM inverter," IEEE Trans. Energy Convers., Vol. 25, No. 1, pp. 1-10, Mar. 2010.

[3] L. M. Gong and Z. Q. Zhu, "A novel method for compensating inverter nonlinearity effects in carrier signal injection-based sensorless control from positive-sequence carrier current distortion,” IEEE Trans. Ind. Applicat., Vol. 47, No. 3, pp. 1283-1292, May/Jun. 2011.

[4] D. E. Salt, D. Drury, D. Holliday, A. Griffo, P. Sangha, and A. Dinu, "Compensation of inverter nonlinear distortion effects for signal-injection-based sensorless control,” IEEE
Trans. Ind. Applicat., Vol. 47, No. 5, pp. 2084-2092, Sep./Oct. 2011.

[5] A. Cichowski and J. Nieznanski, "Self-tuning dead-time compensation method for voltage-source inverters," IEEE Power Electron. Lett., Vol. 3, No. 2, pp. 72-75, Jun. 2005.

[6] D. Leggate and R. J. Kerkman, "Pulse-based dead-time compensator for PWM voltage inverters,” IEEE Trans. Ind. Electron., Vol. 44, No. 2, pp. 191-197, Apr. 1997.

[7] Z. Zhang and L. Xu, "Dead-time compensation of inverters considering snubber and parasitic capacitance,” IEEE Trans. Power Electron., Vol. 29, No. 6, pp. 3179-3187, Jun. 2010.

[8] P. J. Patel, V. Patel, and P. N. Tekwani, "Pulse-based dead-time compensation method for selfbalancing space vector pulse width-modulated scheme used in a three-level inverter-fed induction motor drive," IET Power Electron., Vol. 4, No. 6, pp. 624-631, Jul. 2011.

[9] A. R. Munoz and T. A. Lipo, "On-line dead-time compensation technique for open-loop PWM-VSI drives," IEEE Trans. Power Electron., Vol. 14, No. 4, pp. 683-689, Jul. 1999.

[10] C. Attaianese and G. Tomasso, "Predictive compensation of dead-time effects in VSI feeding induction motors," IEEE Trans. Ind. Appl., Vol. 37, No. 3, pp. 856-863, May/Jun. 2001.

[11] J. W. Choi and S. K. Sul, "Inverter output voltage synthesis using novel dead-time compensation," IEEE Trans. Power Electron., Vol. 11, No. 2, pp. 221-227, Mar. 1996.

[12] H.-S. Kim, H.-T. Moon, and M.-J. Youn, “On-line dead-time compensation method using disturbance observer,” IEEE Trans. Power Electron., Vol. 18, No. 6, pp. 1336-1345, Nov. 2003.

[13] S.-Y. Kim, W. Lee, M.-S. Rho, and S.-Y. Park, "Effective dead-time compensation using a simple vectorial disturbance estimator in PMSM drives,” IEEE Trans. Ind. Electron., Vol. 57, No. 5, pp. 1609-1614, May 2010.

[14] N. Urasaki, T. Senjyu, K. Uezato, and T. Funabashi, "Adaptive dead-time compensation strategy for permanent magnet synchronous motor drive,” IEEE Trans. Energy Convers., Vol. 22, No. 2, pp. 271-280, Jun. 2007.

[15] A. M. Hava, R. J. Kerkman, and T. A. Lipo, "Simple analytical and graphical methods for carrier-based PWM-VSI drives,” IEEE Trans. Power Electron., Vol. 14, No. 1, pp. 49-61, Jan. 1999.

[16] S. Li, C. Xia, and X. Zhou, "Disturbance rejection control method for permanent magnet synchronous motor speed-regulation system,” Mechatronics, Vol. 22, No. 6, pp. 706-714, Sep. 2012.

[17] J. Han, "From PID to active disturbance rejection control," IEEE Trans. Ind. Electron., Vol. 56, No. 3, pp. 900-906, Mar. 2009.

[18] S. Li and Z. Liu, “Adaptive speed control for permanent-magnet synchronous motor system with variations of load inertia," IEEE Trans. Ind. Electron., Vol. 56, No. 3, pp. 3050-3059, Aug. 2009.

[19] H. Liu and S. Li, "Speed control for PMSM servo system using predictive functional control and extended state observer,” IEEE Trans. Ind. Electron., Vol. 59, No. 2, pp. 1171-1183, Feb. 2012. 


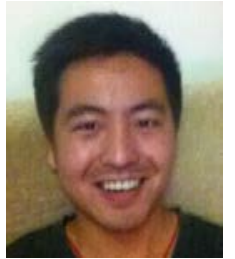

Jie Shi was born in 1990 in Wuhan, China. He received his B.S. degree in Automation in 2012 from Shenyang University of Technology, Shenyang, China. He is currently working toward his M.S. degree at the School of Automation, Southeast University, Nanjing, China. His research interests include control of electrical machines and power electronics.

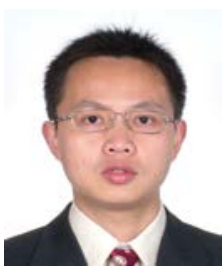

Shihua Li was born in 1975 in Pingxiang, China. He received his B.S., M.S., and Ph.D. degrees all in Automatic Control in 1995, 1998, and 2001, respectively, from Southeast University, Nanjing, China. Since 2001, he has been with the School of Automation, Southeast University, where he is presently working as a Professor. His main research interests include nonlinear control theory and its application to robots, spacecrafts, AC motors, and other mechanical systems. 